\title{
Absolute Configuration of Bromofluoroiodomethane after Preparative Gas Chromatographic Separation
}

\author{
Benjamin Spenger $^{(a)}$, Stefan Näf, Stole Manov ${ }^{(b)}$ \\ and Jürgen Stohner $\left.{ }^{*}\right)$ \\ Zurich University of Applied Sciences (ZHAW) \\ Institute of Chemistry and Biotechnology (ICBT', \\ Einsiedlerstrasse 31, CH-8820 Wädenswil, Swit-erlana
}

Keywords: CHBrFI, preparative gas chronatrrraphy, chiral stationary phase, enantio-separation, halomethane

Revised Vers on $\mathrm{t}, \mathrm{b}$ be submitted to: XXX (rev. Version 25 September 2021)

(*, Corre spondence Author:

Prof. Ir. Jürgen Stohner

Zurich University of Applied Sciences (ZHAW)

Institute of Chemistry and Biotechnology (ICBT)

Einsiedlerstrasse 31, CH-8820 Wädenswil, Switzerland

Email: sthj@zhaw.ch 
Abstract

The enantiomers of bromofluoroiodomethane (CHBrFI) were separated on a preparative scale using gas chromatography (GC). The collected single enantiomers were analysed by vibrational circular dichroism spectroscopy and polarimetry in combination with $a b$ initio calculations to determine the respective absolute configuration. We determined $(\mathrm{S})(+)-$ and $(\mathrm{R})(-$ )-CHBrFI with specific optical rotatory power $[\alpha]_{D}^{26}$ of $(5.51 \pm 0.39)$ and ($5.39 \pm 0.23)^{\circ} \mathrm{cm}^{3} \mathrm{~g}^{-1} \mathrm{dm}^{-1}$, respectively.

In order to achieve the enantio-separation, a new chiral stationary nha (CSP) has been synthesized. This CSP, based on $\alpha$-cyclod xtri. e, is capable of separating a number of halomethanes and their deriv tive on a preparative scale and thus opens the way to collect enantio ers pue oi enriched up to a gram-scale within weeks in an efficient aritumau à manner. 


\section{Introduction}

Space missions are equipped with chiral columns to investigate chiral (large) molecules in outer space (see ${ }^{[1]}$ and refs. therein). It is expected that the analysis will shed some light on the formation of the solar system and the origin of life. ${ }^{[2-4]}$ This underlines the importance of chiral molecules in many areas related to chemistry and biology, ${ }^{[5]}$ however, these molecules are more likely large compared to the small molecules which are of particular inierest here.

Small chiral halomethanes and oxiranes are ideal prototype mol॰cules for the investigation of chiroptical properties (rotational angle, ${ }^{[6]}$ (-vibra ${ }^{\text {innal }}$ ) circular dichroism, ${ }^{[7]}$ photo-electron circular dichroism, ${ }^{[8,9]}$ euc.). The syn-

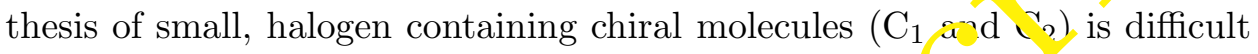
and has not been performed with high versatility in th pas', however, we devised a versatile and efficient synthetic route to achie ${ }^{-}$tnıs for chiral halogenated acetic acids. ${ }^{[10]}$ Similarly difficult is the eparstion of enantiomers of such small compounds, where it is still a gre ${ }^{2}$ chalenge to crystallize the target molecules.

Chiral derivatization and measurement of ${ }^{\top} \mathrm{M} R$ anisotropy between two diastereomers can be used to determir o th absolute configuration, ${ }^{[11]}$ as well as enzymatic methods which rely $\urcorner n$ i.de enantio-preference of enzymes. ${ }^{[12]}$ Recent developments explore th ${ }^{\prime}$-wave mixing techniques in the microwave spectral region to distinguish botn enantiomers and the racemic in a mixture. ${ }^{13]}$ Except $X$-iay crystallography, such methods are 'indirect' methods: they require son a adc 'tional 'input' (reference material, empirical rules, $a b$ initio calculations, tc.) to resolve the absolute configuration.

Pitzer et al. ${ }^{[14}$ u c a laser to ionize and fragment target molecules (Coulomb Explosion (mmarins, CEI) ${ }^{[15]}$ to determine the spatial structure of gas-phase chirar nole ules. In contrast to $X$-ray crystallography, this method works - 'so for i xrget compounds which do not crystallize but require rather large qui titics at present. Similarly, one can use ionization and immediate fragmentation upon sending the target molecule through a thin foil, ${ }^{[16]}$ however, this technique is limited to rather light atoms. Those CEI techniques are 'direct' methods because one 'observes' the structure in a direct way.

Small chiral molecules $\left(\mathrm{C}_{1}\right.$ and $\left.\mathrm{C}_{2}\right)$ are suited for high-quality computational methods, appear as gases or have at least a relatively high vapour pressure. 
This allows to study them in the gas-phase as 'isolated' molecules where intermolecular interactions are suppressed or absent; this in turn facilitates spectroscopic investigations and analysis. ${ }^{[17]}$

Some recent fundamental research dealing with enantio-pure or enantioenriched samples of small chiral molecules concern the measurement of molecular parity violating effects. ${ }^{[18,19]}$ Particularly for the measurement of frequency shifts, one relies on enantio-pure target molecules containing heavy nuclei ${ }^{[18,20-22]}$ and a thorough understanding of high-resolution Jvibrational spectra. ${ }^{[17,23,24]}$ Table 1 shows chiral halomethanes and dorive.

\begin{tabular}{|c|c|c|}
\hline Target & $\begin{array}{l}\text { Yield } \\
\end{array}$ & $\overline{\text { Selectivity; Abs. Config., }} \overline{1_{5 g 9}^{25}}$ \\
\hline $\mathrm{CHClFCOOH}^{[25,26]}$ & 9 to $16 \%$ & 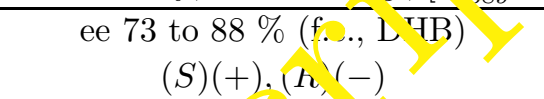 \\
\hline $\begin{array}{l}\mathrm{CH}_{3} \mathrm{CHXCOOR}^{\prime 27]} \\
\left(\mathrm{X}=\mathrm{Br}, \mathrm{Cl} ; \mathrm{R}^{\prime}=\text { n-butyl }\right)\end{array}$ & $72 \%$ & ee $>31 \%$ (enzymatic) \\
\hline $\mathrm{CHClFI}^{[28,29]}$ & 33 to $42 \%$ & $\begin{array}{c}\text { ee } 63(2 \%) \text { f.c., strychnine }) \\
(S)(+),\left({ }^{3}\right)(-) ; \pm 2.5^{\circ} \mathrm{cm}^{3} /(\mathrm{g} \mathrm{dm})\end{array}$ \\
\hline $\mathrm{CHBrFCOOH}^{[30]}$ & $52 \%$ & $\begin{array}{c}\text { e } 84 \% \text { (f.c., strychnine); } \\
(S)(+),(R)(-)\end{array}$ \\
\hline $\mathrm{CHBrClF}^{[31-34]}$ & $52 \%$ & $\begin{array}{l}-\mathrm{et} \\
56-72 \% \text { (f.c., strychnine); } \\
(S)(+),(R)(-) ; \pm 1.6^{\circ} \mathrm{cm}^{3} /(\mathrm{g} \mathrm{dm})\end{array}$ \\
\hline
\end{tabular}

Table 1: Various synthesizє hal nethanes and derivatives for use in enantio-separation with coir spon ing yield, enantiomeric excess (f.c.: fractional crystallization, DHB: d`nydroabietylamine), absolute configuration and specific opt cal - tatory power, $[\alpha]_{589}^{25}$.

tives so far synthesis id in racemic form and enantio-separated. CHClFI is the only target which has been prepared on 'large scale' (about $250 \mathrm{mg}^{[28]}$ ). As can $\rightsquigarrow$ seen rrom Table 1 , enantio-separation was achieved almost exIusivel, by factional crystallization. More often than not, no crystals are $\mathrm{O}_{\mathrm{L}}$ 'ained and therefore, other separation methods are required. An elegant but ' $c 0$ difficult route would be the asymmetric synthesis of the respective targets since every single class of targets would need a new reaction scheme for asymmetric synthesis. ${ }^{[35]}$ However, a rather universal method for enantio-separation or enantio-enrichment of our target molecules is gas chromatography (GC). ${ }^{[5]}$ The small target compounds are liquids with an appreciable vapour pressure and are sufficiently thermally stable (below 70 
$\left.{ }^{\circ} \mathrm{C}\right)$ to separate them on a chiral stationary phase (CSP). Since we are interested in a rather large amount, preparative columns are needed. It is well known that scale-up from an analytical to a preparative column does not work in general, there is no guarantee that a CSP which separates enantiomers on an analytical column also separates on a preparative column. ${ }^{[36]}$ Therefore, synthesis of new CSPs which are capable to separate the target compounds on a preparative scale are required.

After extensive exploring and testing, we were able to synthesize a sui ble CSP based on alkylated $\alpha$-cyclodextrine. ${ }^{[37-40]}$ A wide variety of larg ${ }^{\text {n }}$ molecules were separated successfully by cyclodextrine derived $\mathrm{C}^{\mathrm{r}} \mathrm{J}_{\mathrm{s}}$ or an analytical scale ${ }^{[36]}$ in the past. Our CSP, however, is able to sepa ate wide variety of our $\mathrm{C}_{1}$ and $\mathrm{C}_{2}$ target compounds very efficientl either at room temperature or at temperatures slightly below $0{ }^{\circ} \mathrm{C}$ on a rreparc +ive scale. ${ }^{[38]}$ Depending on how well the peaks are separated on the re sntion time scale, a very high enantiomeric excess can be achieved and tin pro duction of enantiopure samples with preparative GC is faster than rac vional crystallization. Until now, GC resolution of $\mathrm{CHBrClF}, \mathrm{CHClF}_{1}$, and $\mathrm{CHBrClCF}_{3}$ has been achieved only on an analytical scale witr- capı.' 2 ry columns. ${ }^{[39,41]}$

\section{Experimental Section}

The synthesis of bromofluc iode nethane, CHBrFI, was performed following the procedure described $\mathrm{b}$. Li et al. ${ }^{[42]}$ Hexakis(2,3,6-tri- $O$-butyl)- $\alpha$ cyclodextrine, vas trained from $\alpha$-cyclodextrine (1,4-glycocidic connection of $D(+)$-glu. ise) rith 1-bromobutane as the only alkylation reagent following the doscrip ${ }^{+i}$ on for similar compounds. ${ }^{[39]}$ An early synthesis of hexakis $\left(2,3,6\right.$ ri-c butyl)- $\alpha$-cyclodextrine was reported ${ }^{[40]}$ to investigate its reductive leavase, but it has never been used as chiral stationary phase in $G_{\mathbb{S}}$. W dis: jived it in polysiloxane and packed a column (length about 2 $\mathrm{n} .5 .3 \mathrm{~nm}$ inner diameter), CHBrFI was separated by GC and collected with home-built fraction collector. This CSP separates a large variety of halomethanes and derivatives (e.g. amines and esters) of the corresponding acetic acids. ${ }^{[10]}$ The VCD spectra were recorded on a BioTools ChiralIR $2 X$ spectrometer. For detailed experimental procedures, see the Supporting Information. 


\section{Results and Discussion}

Some fundamentals of the infrared spectrum of CHBrFI have been measured before ${ }^{[42,43]}$ and can be compared to ab initio calculations. ${ }^{[44]}$ Table 2 shows the measured and the corresponding calculated frequencies, which were obtained from Moller-Plesset perturbation theory (MP2) and coupled cluster singles-doubles calculations including noniterative triple contributions $(\mathrm{CCSD}(\mathrm{T}))$. Schwerdtfeger et al. ${ }^{[44]}$ applied scalar relativistic pseuriopotentials for the heavy I and $\mathrm{Br}$ atoms and correlation-consistent valer ${ }^{\circ} \mathrm{e}$ double-zeta (cc-pVDZ) basis sets. Column 4 shows MP2 calculations 1 ith a larger (L) basis set of triple-zeta quality (cc-pVTZ) to assess the in ${ }^{T_{1}}$ wence of the basis set size. The values from $\operatorname{CCSD}(T)$ show best arreen vat vith the experimental data, however, the calculated frequencis wt o obtained in the harmonic approximation, which is strictly not com arable to observed anharmonic values. We should note that these calcr ${ }^{1-i o n s}$ and ours presented in Table 3 do not provide frequencies in the rar we of 735 to $909 \mathrm{~cm}^{-1}$ and therefore, it is likely that the observed $\mathrm{b} \cdot \mathrm{nds}^{\left.{ }^{12}, 43\right]}$ do not belong to fundamentals of CHBrFI.

\begin{tabular}{|c|c|c|c|c|c|c|c|}
\hline \multirow[b]{2}{*}{ No. } & \multirow{2}{*}{$\begin{array}{c}\text { Exp. } \\
\text { This work }{ }^{a}\end{array}$} & \multirow[b]{2}{*}{ Exp. ${ }^{[42]}$} & \multirow[b]{2}{*}{ Exp. ${ }^{\left[43^{3}\right.}$} & \multirow[b]{2}{*}{ Ex.p. ${ }^{[45]}$} & \multicolumn{3}{|c|}{ Calc. ${ }^{[4]}$} \\
\hline & & & & & MP2 & $\mathrm{MP} 2 / \mathrm{L}$ & $\operatorname{CCSD}(\mathrm{T})$ \\
\hline 2 & 1291 & & & & & & \\
\hline 3 & 1141 & 1132 & & 1139.35 & 1204 & 1195 & 1179 \\
\hline 4 & 1061 & 1044 & & 1060.85 & 1102 & 1106 & 1100 \\
\hline & & $\begin{array}{l}909^{b} \\
735^{b}\end{array}$ & $\begin{array}{l}508.6^{b} \\
735.3^{b}\end{array}$ & & & & \\
\hline 5 & 687 & 6,2 & 673.2 & 686.5 & 683 & 718 & 654 \\
\hline 6 & & & & & 568 & 589 & 552 \\
\hline 7 & & & & & 334 & 347 & 326 \\
\hline
\end{tabular}

Truic n. E nerimental band centres and earlier ab initio calculated harmonic 'indame itais (both in $\mathrm{cm}^{-1}$ ). ${ }^{a}$ With our setup we cannot measure below $40 \mathrm{~cm}^{-}$; two weak bands around 2975 and $3125 \mathrm{~cm}^{-1}$ are observed and might be the $\mathrm{CH}$-stretching perturbed by (Fermi) resonance interaction. An additional peak at $2104 \mathrm{~cm}^{-1}$ is likely due to a CF-stretch overtone $\left(p(\mathrm{CHBrFI})=6\right.$ mbar, resolution $0.5 \mathrm{~cm}^{-1}$, see Supporting Information $) .{ }^{b}$ indicates that the assignment as a fundamental is probably incorrect. 
This is also supported by our measurements of the infrared band centers between 400 and $4200 \mathrm{~cm}^{-1}$ (reproduced in the Supporting Information). In order to determine the absolute configuration, we need to measure the VCD spectrum and compare the relative signs of the signals with those from calculations of the respective enantiomers. For the measurement of the VCD spectra, it is necessary to obtain enantio-separated CHBrFI and as an example, Figure 1 shows a chromatogram of the successful separation. Two fractions appear between 80 and $110 \mathrm{~min}$ and are baseline separ ced

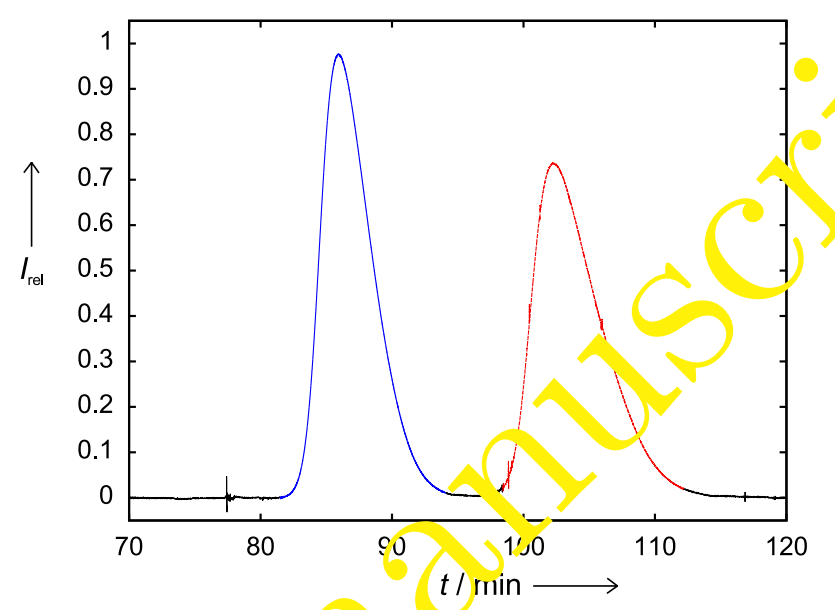

Figure 1: Chromatogram of $\mathcal{}$ 'HB $\mathrm{FI}$ between 70 and 120 minutes retention time. One can distinguish an early Fraction 1 (blue) and a later Fraction 2 (red) on our SSF. CHBrFI was injected dissolved in $\mathrm{CCl}_{4}$. The chromatogram for the rreparative collection is reproduced in the Supporting Information.

for entir $i \min$. This facilitated the preparative collection by an algorithm , nat co, rol: switching between two cold traps of our home-built fraction c " 'ector for both enantiomers. The resolution obtained is $R=1.07$ and the s yaration factor is $\alpha=1.23$. A separation factor $\alpha>1.3$ is often considered a prerequisite for the preparative application of racemic separations based on selective guest-host interactions, for which cycledextrines are representatives. ${ }^{[46]}$

The experimental VCD spectrum in the range between 1000 and $1200 \mathrm{~cm}^{-1}$ is shown in Figure 2 and can be compared to our ab initio calculated VCD 
spectrum. Figure 2(a) shows the two VCD raw signals of both collected enantiomers which are mirror images of each other (solid blue line and dotted red line). This shows that the occurring peaks are truly due to enantioseparation. The calculated VCD spectrum of $(S)$-CHBrFI is shown in Figure 2(b), it was obtained using DFT (convoluted to guide the eye). From the relative sign of the main peaks it can be inferred that Fraction 1 of the chromatogram corresponds to $(S)$-CHBrFI (solid line, blue) and consequently Fraction 2 to $(R)$-CHBrFI (dotted line, red). Figure 2(c) reproduce the experimental IR spectrum of the racemate. The calculated IR sportrun considering anharmonic corrections ${ }^{[48]}$ are shown in Figure $\left.2^{(} d\right)$, s. hich 1 epresents a gas-phase spectrum; however, no pronounced effects ca sed v the solvent are expected other than broadening and minor shif

We used MP2 and density functional theory (DFT) vii the B3LYP functional, the latter is capable to provide also VCD intn onlies. ${ }^{[48]}$ We used the same basis set (Stuttgart-Dresden-Bonn cc-pVT'z hasis set with pseudopotentials for the heavy atoms $\mathrm{Br}$ and I) for bot. methods. The geometries were fully optimized both for MP2 and $1 \mathrm{~F}^{\prime} \perp$ alculations. The harmonic frequencies, $\tilde{\omega}$, and the correspondirs anh inonically corrected values, $\tilde{\nu}$, which were obtained perturbatively fr on che quartic force field are reproduced in Table 3 and given in paren. hesis. The calculated infrared intensities and the VCD signal intensit es a "e also tabulated. The intensities are obtained in the double harmonic , nproximation. More details on the computations can be found in the Supporting Information. The agreement between the calculated $M_{2}$ ? ha. no nic frequencies shown in Tables 2 and 3 are good. One would expect t $t_{-}$? $\operatorname{CCSD}(\mathrm{T})$ results of better quality, but this is difficult to judge by orat rison with experiment, because no anharmonically corrected frrruenc so were calculated. ${ }^{[44]}$ Our anharmonically corrected band cunters re ifficiently close to experiment and could serve as a basis for the c tailed nderstanding of the vibrational dynamics of CHBrFI in the fundamen 7 l fegion. From our experience with halomethanes carrying an isolated $\mathrm{CH}$-chromophore, we rather expect strong multi-dimensional anharmonic resonance interactions which would alter the band positions as well as the intensities. This has been shown in the past for $\mathrm{CHBrClF}$ and $\mathrm{CDBrClF}$ up to very high overtone excitation as well as for such tiny effects like the computed parity violating contributions. ${ }^{[22,49,50]}$ 


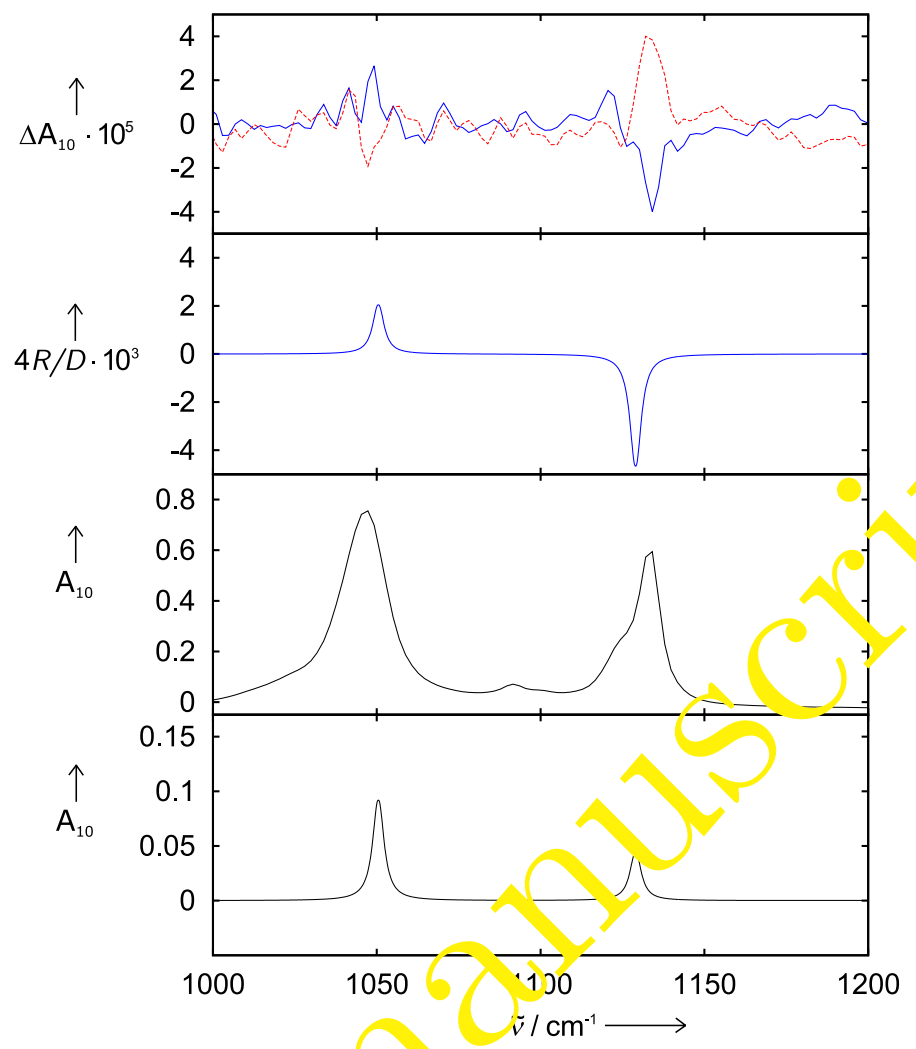

Figure 2: Part of the VCD a. 1 IR spectra between 1000 and $1200 \mathrm{~cm}^{-1}$. The quantity $A_{10}$ or $\Lambda_{1}$ is the decadic absorbance. ${ }^{[47]} \Delta A_{10}$ is the VCD signal as difference in ( 1 caa - ) absorbances of left and right circularly polarized light. (a) Experime, tal VCD spectrum of Fraction 1 (solid line, blue) and Fraction 2 (cot $\mathrm{e}^{\prime}$ ine, red) dissolved in $\mathrm{CCl}_{4}(m=0.251 \mathrm{~mol} / \mathrm{kg}$, about 9000 sperra (․ 1) superimposed, baseline has been corrected against the racema ; re slution $4 \mathrm{~cm}^{-1}$. See Supporting Information for more details c. variou s baseline correction schemes.) (b) Ab initio calculated VCD spectrum of $(S)$-CHBrFI (B3LYP, SDB ccpVTZ P basis set, see Text). (c) Experimental IR spectrum dissolved in $\mathrm{CCl}_{4}(m=0.251 \mathrm{~mol} / \mathrm{kg}$, resolution $4 \mathrm{~cm}^{-1}, 10$ scans superimposed). (d) Ab initio calculated IR spectrum of $(S)$-CHBrFI (B3LYP, SDB ccpVTZ P basis set, see Text). The IR frequencies have been corrected anharmonically by using the quartic force field. ${ }^{[48]}$ 


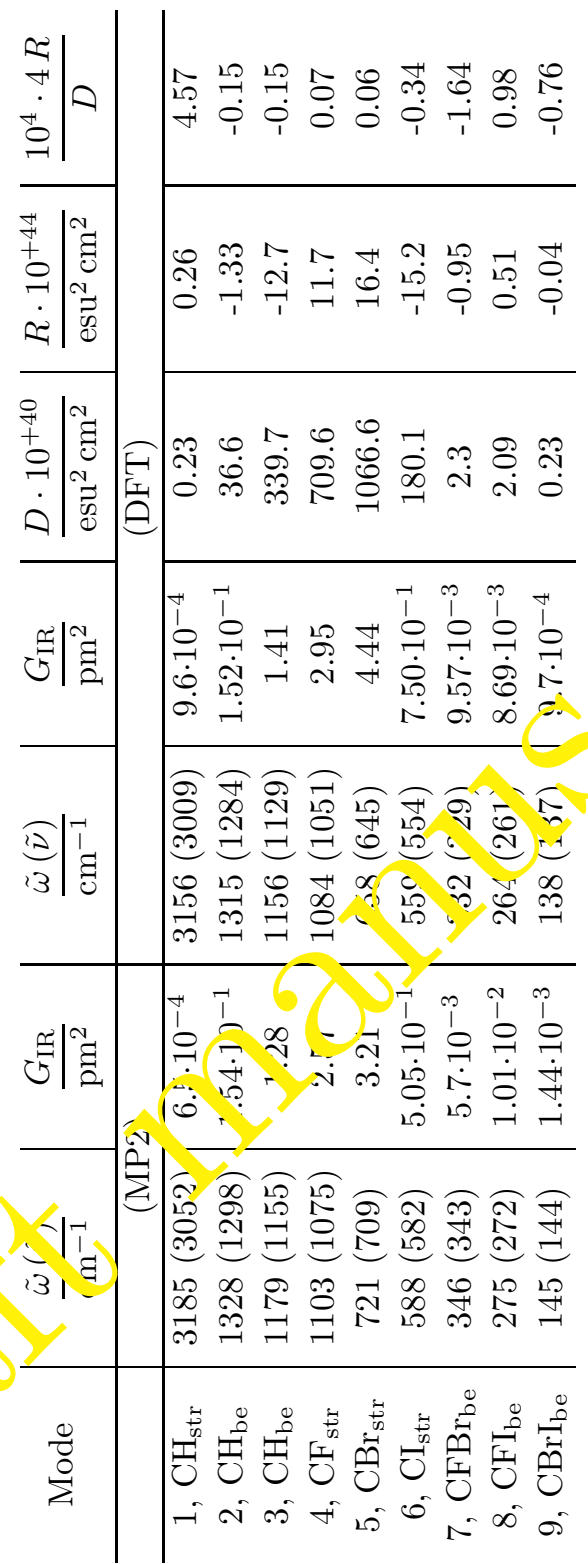

Table 3: Ab initio calculated (MP2 and DFT, Stuttgart-Dresden-Bonn cc-pVTZ basis set with pseudopotentials for $\mathrm{Br}$ and I) fundamental (str: stretch, be: bend) harmonic $(\tilde{\omega})$ and anharmonically corrected $(\tilde{\nu})$ frequencies, the latter are given in parenthesis. $G_{\mathrm{IR}}$ denotes the infrared band strength (in $\mathrm{pm}^{2}$ ), $D$ the dipole strength (in $10^{-40} \mathrm{esu}^{2} \mathrm{~cm}^{2}$ ), $R$ the rotatory strength (in $10^{-44} \mathrm{esu}^{2} \mathrm{~cm}^{2}$ ); $4 R / D$ signifies the VCD signal ${ }^{[48,51]}$ (for more details, see the Supporting Information). 
The absolute configuration requires the determination of the specific optical rotatory power, $[\alpha]_{\mathrm{D}}^{26}$. This quantity if often called "specific rotation" and quoted without units; here we follow the IUPAC terminology (see Section 2.7.1 in $\left.{ }^{[47]}\right)$. The specific optical rotatory power assigns a plus or minus sign to the $R$ or $S$ configurational label. For Fraction $1,[\alpha]_{589}^{26}$ is equal to $(5.51 \pm 0.38)^{\circ} \mathrm{cm}^{3} \mathrm{~g}^{-1} \mathrm{dm}^{-1}\left(c=0.341 \mathrm{~g} \mathrm{~cm}^{-3}, \mathrm{CCl}_{4}, d=0.05 \mathrm{dm}, n=10\right.$, $99 \%$ confidence interval) and the corresponding value for Fraction 2 is equal to $(-5.39 \pm 0.23)^{\circ} \mathrm{cm}^{3} \mathrm{~g}^{-1} \mathrm{dm}^{-1}\left(c=0.326 \mathrm{~g} \mathrm{~cm}^{-3}, \mathrm{CCl}_{4}, d=0.05 \mathrm{dm} . \iota=\right.$ 10, $99 \%$ confidence interval). Those values have been obtained by takino $t_{1}$ ? separately determined different enantiomeric excess (ee) for Tract. in 1 . nd 2 into account. The values for the specific optical rotatory powe ${ }^{n}$ are equal in magnitude within experimental uncertainty (see Support: ng Int,rmation for details). We calculated the specific optical rotatory powt. at different wavelength by DFT (with B3LYP functional) for vario : basis sets at four different wavelength, details are provided in the $\mathrm{Su}_{+}^{m}$, or ing Information.

\begin{tabular}{c|c|c|c|c|} 
& $589 \mathrm{~nm}$ & $546 \mathrm{~nm}$ & $45 \mathrm{~nm}$ & $405 \mathrm{~nm}$ \\
\hline Theory & 5.0 & 6.7 & 19.0 & 30.9 \\
Exp. & $5.51 \pm 0.38$ & $7.02 \pm 0.38$ & $0.0 \% \pm 0.60$ & $32.20 \pm 0.60$
\end{tabular}

Table 4: Specific optical rotatory $r$ ov or of $(S)$-CHBrFI calculated at

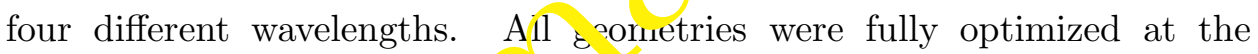
DFT/B3LYP level (cc-pVT:L-F ' basis). More results for different basis sets with and without pseudo notential are collected in the Supporting Information.

Independent $f^{r}$ the 1 asis sets used, the specific optical rotatory power is always positive fo the $S$-configuration of CHBrFI and increases with decreacing $n$ velength; the basis cc-pVTZ-PP compares best with the expermental. de cermined values (see Table 4 and Table 3 of the Supporting Ir. vrmat on). We can conclude from our experiments and the theoretical a. Alysis that the absolute configuration of bromofluoroiodomethane is therefore $(S)(+)$-CHBrFI and $(R)(-)$-CHBrFI, as is the case for similar compounds, collected in Table 1.

We demonstrated efficient enantio-separation of CHBrFI by preparative GC with our CSP and determined the absolute configuration to be $(S)(+)$ - 
CHBrFI and $(R)(-)$-CHBrFI with the aid of VCD spectroscopy and $a b$ initio calculations. An enantio-separation of a halomethane on a preparative scale with a chiral stationary phase in gas-chromatography was not reported before. We should mention that with our autosampler and homebuilt fraction collector system, we are able to collect 200 to $400 \mathrm{mg}$ per week in an automated fashion. This is an enormeous improvement over current techniques towards enantio-separation of halomethanes on a large scale.

\section{Acknowledgement}

We gratefully acknowledge help from and discussions with Or. H. Hollenstein, former group members F. Deuber, F. Hobi and M Mazeı uuer, as well

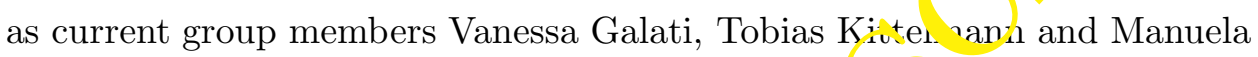
Meister. This work was part of the MSc Thesis or ' Jen amin Spenger and was funded by the ZHAW through grants AF 201 '/1 and AF 2015/1. We thank the Computer Center of ETH for gersou computation time.

\section{References}

[1] I. Myrgorodska, T. Javell, C. I' 'rinert, U. J. Meierhenrich, Israel Journal of Chemistry 2016, 56, 1,16-1026.

[2] M. Quack, Angors. Chem. Intl. Ed. (Engl.) 2002, 41, 4618-4630.

[3] C. Viedma, 1. Cintas, Israel Journal of Chemistry 2011, 51, 997-1006.

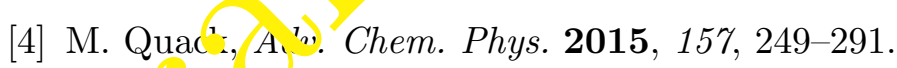

[5] - Lo enz, A. Seidel-Morgenstern, Angew. Chem. Intl. Ed. (Engl.) 201 !, 53, 1218-1250.

[6] ' Lahiri, K. B. Wiberg, P. H. Vaccaro, J. Phys. Chem. A 2015, 119, 8311-8327.

[7] P. L. Polavarapu, Chirality 2012, 24, 909-920.

[8] M. H. M. Janssen, I. Powis, Phys. Chem. Chem. Phys. 2014, 16, 856871. 
[9] C. Lux, M. Wollenhaupt, T. Bolze, Q. Liang, J. Köhler, C. Sarpe, T. Baumert, Angew. Chem. Intl. Ed. (Engl.) 2012, 51, 5001-5005.

[10] M. R. Mazenauer, S. Manov, V. M. Galati, P. Kappeler, J. Stohner, RSC Adv. 2017, 7, 55434-55440.

[11] T. J. Wenzel, C. D. Chisholm, Chirality 2011, 23, 190-214.

[12] Q. Jing, R. J. Kazlauskas, Chirality 2008, 20, 724-735.

[13] D. Patterson, M. Schnell, J. M. Doyle, Nature 2013, 497, 475-4r:

[14] M. Pitzer, M. Kunitski, A. S. Johnson, T. Jahnke, H. Sarı, F. urm, L. P. H. Schmidt, H. Schmidt-Böcking, R. Dörn r, J. stohner, J. Kiedrowski, M. Reggelin, S. Marquardt, A. Schief,e1, R. ? erger, M. S. Schöffler, Science 2013, 341, 1096-1100.

[15] Z. Vager, R. Naaman, E. P. Kanter, Scienc. 1989 244, 426-431.

[16] P. Herwig, K. Zawatzky, M. Grieser, O. '`ober, B. Jordon-Thaden, C. Krantz, O. Novotny, R. Repnow,' 'T Sc. urig, D. Schwalm, Z. Vager, A. Wolf, O. Trapp, H. Kreckel, sc snce 2013, 342, 1084-1086.

[17] F. Hobi, R. Berger, J. Stohne. Nui. Phys. 2013, 111, 2345-2362.

[18] M. Quack, J. Stohner, I' W ileke, Annu. Rev. Phys. Chem. 2008, 59, $741-769$.

[19] R. Berger, C Cou tieu, R. R. Gil, C. Griesinger, M. Köck, P. Lesot, B. Luy, D. Mer †t. A. Navarro-Vázquez, M. Reggelin, U. M. Reinscheid, C. M. T'ifie, M. Zweckstetter, Angew. Chem. Intl. Ed. (Engl.) 2012, 51, , $988-8 \div 1$.

?0] M. Uuack, J. Stohner, Phys. Rev. Lett. 2000, 84, 3807-3810.

[21] ᄀ Berger, M. Quack, J. Stohner, Angew. Chem. Intl. Ed. (Engl.) 2001, 40, 1667-1670.

[22] M. Quack, J. Stohner, J. Chem. Phys. 2003, 119, 11228-11240.

[23] H. Hollenstein, D. Luckhaus, J. Pochert, M. Quack, G. Seyfang, Angew. Chem. Intl. Ed. (Engl.) 1997, 36, 140-143. 
[24] R. Berger, G. Laubender, M. Quack, A. Sieben, J. Stohner, M. Willeke, Angew. Chem. Intl. Ed. (Engl.) 2005, 44, 3623-3626.

[25] G. Bellucci, G. Berti, A. Borraccini, F. Macchia, Tetrahedron 1969, 25, 2979-2985.

[26] G. Bellucci, G. Berti, C. Bettoni, F. Macchia, J. Chem. Soc., Perkin Trans. 2 1973, pp. 292-295.

[27] G. Kirchner, M. Scollar, A. Klibanov, J. Am. Chem. Soc 1985, I^ף, 7072-7076.

[28] J. Crassous, Z. Jiang, V. Schurig, P. L. Polavarapu, Tetrahedı n: ^ «mmetry 2004, 15, 1995-2001.

[29] P. Soulard, P. Asselin, A. Cuisset, J. Moreno, T. 'Tuet, D. Petitprez, J. Demaison, T. Freedman, X. Cao, L. Nafie, J Casssous, Phys. Chem. Chem. Phys. 2006, 8, 79-92.

[30] H. Boussac, J. Crassous, J. Dutasta, L. Trosvalet, A. Thozet, Tetrahedron: Asymmetry 2002, 13, 975-981.

[31] J. Costante, L. Hecht, P. L. Pora $\operatorname{rar}$ upu, A. Collet, L. Barron, Angew. Chem. Intl. Ed. (Engl.) 1997, 36, 885-887.

[32] J. Costante-Crassous, I. Mar rone, J. Briggs, J. McCammon, A. Collet, J. Am. Chem. Sor. 1997, 119, 3818-3823.

[33] P. Polavarap An or. Chem. Intl. Ed. (Engl.) 2002, 41, 4544-4546.

[34] J. Crassous, T. Monier, J.-P. Dutasta, M. Ziskind, C. Daussy, C. Grain, C. Chardc net, ChemPhysChem. 2003, 4, 541-548.

'35] B. . Fe. Inga, R. A. van Delden, Angew. Chem. Intl. Ed. (Engl.) 1999, $38,: 418-3438$.

[36] `V. Schurig, H. P. Nowotny, Angew. Chem. Intl. Ed. (Engl.) 1990, 29, 939-1076.

[37] B. Spenger, Enantiomerentrennung kleiner chiraler Moleküle und Bestimmung der absoluten Konfiguration mittels Schwingungsdichroismus, MSc Thesis, ZHAW Wädenswil (2013). 
[38] B. Spenger, J. Stohner, Verfahren zur gaschromatographischen Trennung eines Enantiomerengemisches, Patent EP16160863, 17 March 2016.

[39] W. A. König, Gas Chromatographic Enantiomer Separation with Modified Cyclodextrins, Hüthig Buch Verlag, Heidelberg, 1992.

[40] P. Mischnick-Lübbecke, R. Krebber, Carbohydrate Research 1989, 187, 197-202.

[41] Z. Jiang, J. Crassous, V. Schurig, Chirality 2005, 17, 488-49?.

[42] D. B. Li, S.-C. Ng, I. Novak, Tetrahedron 2002, 58, 592?-5!'6.

[43] I. Novak, D. Li, A. Potts, J. Phys. Chem. A 2002. 1J6, 45-468.

[44] P. Schwerdtfeger, J. Laerdahl, C. Chardonnet, Ph॰ı. İev. A 2002, 65, 042508-1-042508-7.

[45] S. Albert, K. K. Albert, S. Bauerecker, M. Wuack, CHBrIF and molecular parity violation: First high te olut, $n$ rovibrational analysis of the CF-stretching mode, Innsbrucn Unı, ersity Press (IUP), Innsbruck, 2008 pp. $79-82$.

[46] Schurig, V. and Grosenick, Ч., J. Chromatography A 1994, 666, 617625.

[47] E. R. Cohe 1, T. Cvitaš, J. Frey, B. Holmström, K. Kuchitsu, R. Marquardt, I. I. 'ls, 1. Pavese, M. Quack, J. Stohner, H. L. Strauss, M. Takanit, A. J. Thor, Quantities, Units and Symbols in Physical Chemistry IUPAC \& The Royal Society of Chemistry, Cambridge, 3rd nditic , 3rd printing edn., 2011.

[. १] M. .. Frisch et al., Gaussian 09, Rev. A.02, Gaussian Inc., Wallingford ¿T. 2009.

[49] J. Stohner, M. Quack, Faraday Discussions 2011, 150, 113-114 and $117-118$.

[50] A. Beil, H. Hollenstein, O. Monti, M. Quack, J. Stohner, J. Chem. Phys. 2000, 113, 2701-2718. 
[51] L. A. Nafie, Vibrational Optical Activity. Principles and Applications, Wiley, Chichester, 2011.

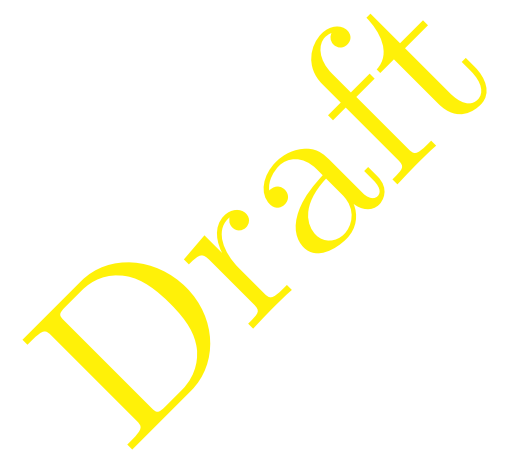

